\title{
Unravelling the secrets of the caecum
}

\author{
Friederike Stumpff $^{1}$ [D $\cdot$ David Manneck $^{1} \cdot$ Holger Martens $^{1}$
}

Received: 5 June 2019 /Revised: 5 June 2019 / Accepted: 6 June 2019 / Published online: 13 June 2019

(C) Springer-Verlag GmbH Germany, part of Springer Nature 2019

Localized at the critical junction between the nonfermentative and fermentative parts of the gut, the caecum has a plethora of poorly understood functions. In herbivorous species, the caecum forms a large, blind pouch in which otherwise indigestible fibres are broken down into energy-rich compounds required for survival (Fig. 1). Conversely, the human caecum and its appendix are generally considered to be vestigial "troublemakers" that require removal in diseases such as inflammatory bowel disease or cancer. Recently, a role in regulating the microbiome in health and disease is being discussed [11] and a better understanding of the organ appears overdue.

As digesta enters from the ileum into the caecum, bacterial counts surge to levels above $10^{11} \mathrm{CFU} / \mathrm{mL}$. The first function of the caecum is clearly to ensure that this dramatic switch occurs in a manner that does not endanger either the epithelium per se or the microbials within. To maintain fermentational homeostasis, microbial products such as short chain fatty acids or ammonia must be absorbed to prevent an accumulation to toxic levels, and buffers must be secreted to maintain an optimal $\mathrm{pH}$ [3]. Equally important, the caecal epithelium must form a tight mechanical and immunological barrier against an efflux of microbials and their toxins into the bloodstream.

The combination of epithelial tightness and high levels of transport invite electrophysiological investigations which yield insights not only concerning the caecal epithelium, but possibly enhancing our understanding of the function and regulation of the underlying transport

Friederike Stumpff

stumpff@zedat.fu-berlin.de

1 Institute of Veterinary Physiology, Department of Veterinary

Medicine, Freie Universität Berlin, Oertzenweg 19b,

14163 Berlin, Berlin, Germany proteins within an intact epithelium. Building on two previous studies published in Pflügers Arch. [1, 2], in the current issue, Pouokam and Diener systematically compare differences in ion transport across two different segments of the rat caecum [8]. As in the classical model, a basolateral NKCC drives secretion via anion channels, possibly delivering $\mathrm{HCO}_{3}{ }^{-}$to deliver protons formed in the fermentational process $[6,10]$. However, amiloride in the micromolar quantities normally known to block ENaC failed to show effects. This finding is in line with previous observations in the proximal rat colon [5] and rabbit caecum [4], with the latter expressing an apical cation conductance permeable to cations as diverse as $\mathrm{Na}^{+}, \mathrm{K}^{+}, \mathrm{Cs}^{+}$ or $\mathrm{Rb}^{+}[13]$. Pouokam and Diener now take the story one step further by showing that in rat, this non-selective cation conductance is sensitive to TRP channel modulators. In a further twist, they demonstrate that both the anionic and the cationic conductances are significantly upregulated by cyclooxygenase metabolites - with signalling strongest in the distal caecum, where metabolites tend to accumulate.

Given the classical observation that the apical membrane of the caecum is poorly permeable to $\mathrm{NH}_{3}$ [3] and that TRP channels are notoriously promiscuous [7], TRP channels may provide a venue for the efflux of $\mathrm{NH}_{4}{ }^{+}$from the caecum, as suggested for the rumen $[9,12]$. Regulation of bicarbonate influx and ammonia efflux by neural and paracrine signalling would certainly enhance the ability of the caecum to regulate caecal $\mathrm{pH}$ and nitrogen levels as key factors in maintaining a healthy microbial equilibrium. 


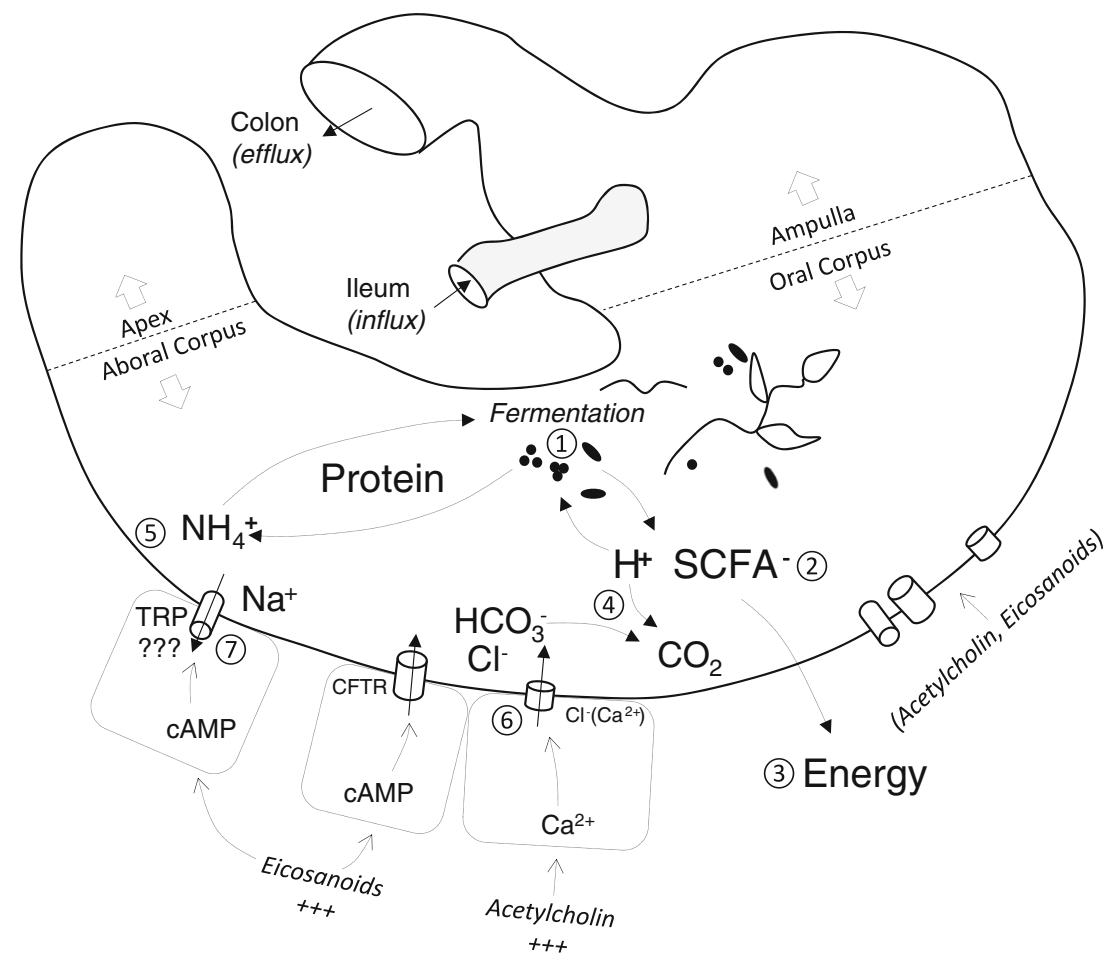

Fig. 1 The primordial function of the caecum is to serve as a fermentation chamber in which otherwise indigestible carbohydrates are fermented by a resident microbial population (1) to release metabolites such as short chain fatty acids (SCFA, (2)) that are utilized to meet the energy demands of the host (3)). In the process, protons and ammonia are produced and must be kept at optimal levels via buffering (4)), microbial protein

\section{References}

1. Bader S, Diener M (2018) Segmental differences in the nonneuronal cholinergic system in rat caecum. Pflugers Arch 470: 669-679. https://doi.org/10.1007/s00424-017-2104-x

2. Bader S, Gerbig S, Spengler B, Schwiertz A, Breves G, Diener M (2019) Robustness of the non-neuronal cholinergic system in rat large intestine against luminal challenges. Pflugers Arch 471:605618. https://doi.org/10.1007/s00424-018-2236-7

3. Busche R, Bartels J, Kirschberger S, von Engelhardt W (2002) Intracellular $\mathrm{pH}$ regulation in guinea-pig caecal and colonic enterocytes during and after loading with short-chain fatty acids and ammonia. Pflugers Arch 444:785-794

4. Clauss W, Schafer H, Horch I, Hornicke H (1985) Segmental differences in electrical properties and Na-transport of rabbit caecum, proximal and distal colon in vitro. Pflugers Arch 403:278-282

5. Fromm M, Hegel U (1978) Segmental heterogeneity of epithelial transport in rat large intestine. Pflugers Arch 378:71-83

6. Kunzelmann K, Gerlach L, Frobe U, Greger R (1991) Bicarbonate permeability of epithelial chloride channels. Pflugers Arch 417: 616-621

7. Owsianik G, Talavera K, Voets T, Nilius B (2006) Permeation and selectivity of TRP channels. Annu Rev Physiol 68:685-717. https:// doi.org/10.1146/annurev.physiol.68.040204.101406 synthesis or efflux (5)). Paracrine and neuronal signalling via eicosanoids and acetylcholine is highest in the aboral parts of the caecum and stimulates anion (6) and cation channels (7)). It is tempting to speculate that the non-selective nature of these conductances plays a role in maintaining fermentational equilibrium.

8. Pouokam E, Diener M (2019) Segmental differences in ion transport in rat cecum. Pflugers Arch. https://doi.org/10.1007/s00424019-02276-1

9. Rosendahl J, Braun HS, Schrapers KT, Martens H, Stumpff F (2016) Evidence for the functional involvement of members of the TRP channel family in the uptake of $\mathrm{Na}(+)$ and $\mathrm{NH} 4(+)$ by the ruminal epithelium. Pflugers Arch 468:1333-1352. https://doi. org/10.1007/s00424-016-1835-4

10. Rubenstein RC (2018) Editorial focus: CFTR-dependent bicarbonate secretion by Calu-3 cells. Physiol Rep 6:e13691. https://doi.org/ $10.14814 /$ phy2.13691

11. Sahami S, Kooij IA, Meijer SL, Van den Brink GR, Buskens CJ, Te Velde AA (2016) The link between the appendix and ulcerative colitis: clinical relevance and potential immunological mechanisms. Am J Gastroenterol 111:163-169. https://doi.org/10.1038/ajg.2015. 301

12. Schrapers KT, Sponder G, Liebe F, Liebe H, Stumpff F (2018) The bovine TRPV3 as a pathway for the uptake of $\mathrm{Na}+\mathrm{Ca} 2+$, and NH4+. PLoS One 13:e193519. https://doi.org/10.1371/journal. pone.0193519

13. Sellin JH, Dubinsky WP (1994) Apical nonspecific cation conductances in rabbit cecum. Am J Physiol 266:G475-G484

Publisher's note Springer Nature remains neutral with regard to jurisdictional claims in published maps and institutional affiliations. 